\title{
Intact Implicit Memory for Novel Patterns in Alzheimer's Disease
}

\author{
Bradley R. Postle, ${ }^{1,3}$ Suzanne Corkin, ${ }^{1}$ and John H. Growdon ${ }^{1,2}$ \\ ${ }^{1}$ Department of Brain and Cognitive Sciences and the Clinical Research Center \\ Massachusetts Institute of Technology \\ Cambridge, Massachusetts 02139 \\ ${ }^{2}$ Department of Neurology \\ Massachusetts General Hospital \\ Boston, Massachusetts 02114
}

\section{Abstract}

Repetition priming is a kind of implicit memory (learning without awareness) that does not depend on the medial temporal-lobe system. For example, the amnesic patient H.M., who underwent bilateral medial temporal-lobe resection, shows intact priming with novel patterns, suggesting that perceptual priming with nonverbal material does not depend on areas critical for explicit memory. A logical candidate for the neural substrate that supports this kind of priming is the peristriate cortex, an area that is relatively spared in Alzheimer's disease (AD). We therefore predicted that $A D$ subjects would be unimpaired on pattern priming. Subjects copied each of six target figures onto dot patterns. After performing a 3-min distractor task, they were given the same dot patterns (without lines) and asked to draw the first figure that came to mind by connecting the dots with straight lines. Subsequently, in a test of recognition (explicit) memory, subjects viewed each of the six patterns of dots that they had copied previously and were asked to indicate which of four possible completions corresponded to the figure that they had copied 3 min earlier. The AD and control groups achieved comparable priming scores, but $\mathrm{AD}$ subjects were significantly impaired in recognizing the patterns explicitly. Our finding of intact pattern priming in $\mathrm{AD}$ provides, for the first

\footnotetext{
${ }^{3}$ Corresponding author.
}

time, evidence that pattern priming depends on the peristriate cortex.

\section{Introduction}

An important goal of contemporary neuroscience is identifying the regions of the adult brain that support different kinds of learning and memory and understanding the mechanisms that underlie these plastic changes (Ungerleider 1995). A principle that is emerging from neuropsychological, neuroimaging, and electrophysiological investigations of implicit memory is that the neural networks recruited to perform a particular task can modify their processing characteristics through repeated performance of a task or through repeated exposure to a stimulus. Thus, regions of motor cortex can change their patterns of activation in association with improved performance of simple motor tasks (Grafton et al. 1995; Karni et al. 1995; T. Brashers-Krug, H. Krebs, S. Rauch, C. Savage, R. Rubin, N. Alpert, A. Fischman, N. Hogan, and E. Bizzi, pers. comm.), and discrete regions of visual cortex can undergo plastic changes in concert with gradual improvement on a perceptual learning task (G. Bertini, A. Karni, P. De Weerd, R. Desimone, and L.G. Ungerleider, pers. comm.; A. Karni, J. Weisberg, F. LaLonde, and L.G. Ungerleider, pers. comm.). Such evidence of plasticity in motor and sensory cortices means that learning and memory are no longer considered the exclusive purview of brain regions that are specialized for mnemonic function.

Repetition priming is a kind of implicit memory (learning without awareness) in which prior exposure to a stimulus facilitates processing of the stimulus or biases the response on subsequent exposures. Repetition priming is typically intact in

LEARNING \& MEMORY 3:305-312 ๔ 1996 by Cold Spring Harbor Laboratory Press ISSN1072-0502/96 \$5.00

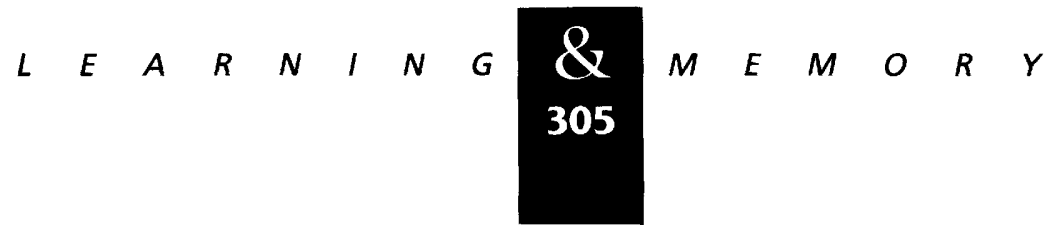


amnesic patients and thus depends on brain areas outside the medial temporal lobe-diencephalic system (Milner et al. 1968; Warrington and Weiskrantz 1970). Repetition priming differs from other types of implicit memory (such as motor learning) in that a single exposure to a stimulus is sufficient to produce learning. Converging evidence now suggests that the posterior visual cortex can undergo rapid plastic change after a single exposure to a stimulus (Squire et al. 1992; Buckner et al. 1995; Schacter et al. 1996; G. Bertini, A. Karni, P. De Weerd, R. Desimone, and L.G. Ungerleider, pers. comm.; A. Karni, J. Weisberg, F. LaLonde, and L.G. Ungerleider, pers. comm.). This change may underlie the facilitation of processing of that stimulus or the biasing of response on subsequent exposures. For example, neuroimaging studies of word-stem completion priming, in which exposure to a word in a study list increases the likelihood that subjects will complete a threeletter stem to that word, indicate that cortical regions responsible for relatively early levels of analysis of the visual scene exhibit a reduction of activation during primed versus unprimed wordstem completions (Squire et al. 1992; Buckner et al. 1995; Schacter et al. 1996). Furthermore, studies of patients with lesions in posterior visual areas have revealed impaired perceptual identification priming, in which subjects identify previously studied words at shorter exposure durations than unstudied words (Gabrieli et al. 1995; Keane et al. 1995).

In an effort to understand the nature of the representations that support repetition priming phenomena, researchers have sought to map out the conditions under which subjects can or cannot demonstrate implicit memory for novel information. Intact priming on a repetition priming test employing novel stimuli provides evidence that the priming phenomenon in question is supported by newly formed, transient representations and does not rely on premorbid mnemonic representations (Haist et al. 1991; Schacter 1992; Squire 1992). Previous work in our laboratory has demonstrated that the amnesic patient H.M. exhibits preserved pattern completion priming with novel, abstract patterns (Gabrieli et al. 1990). Subsequent studies by other groups have replicated this result in amnesic patients of diverse organic etiologies (Musen and Squire 1992; Verfaellie et al. 1992; Gooding et al. 1993, 1994). Because the stimuli used in these studies were presumed to be novel to the subjects, the studies suggested that repetition priming with nonverbal stimuli relies on a low-level, perceptual mechanism. These studies, however, gave no clues about the neural substrate for this implicit memory, beyond the fact that it did not rely on the medial temporal lobediencephalic system that is compromised in amnesia.

Patients with Alzheimer's disease (AD) provide a useful model for investigating the neural substrate of pattern priming because $\mathrm{AD}$ pathology relatively spares low-level, unimodal sensory areas in the neocortex while targeting the high-level, heteromodal cortical regions of frontal, temporal, and parietal cortex (Arnold et al. 1991). A finding of intact pattern priming in $\mathrm{AD}$ would suggest that this kind of nonverbal mnemonic processing, like that seen in repetition priming tasks that employ words (Squire et al. 1992; Buckner et al. 1995; Gabrieli et al. 1995; Keane et al. 1995; Schacter et al. 1996), relies on the peristriate cortex, the belt of unimodal visual cortex (areas 18 and 19) surrounding area 17 (Braak 1980; Mesulam 1985). We predicted, a priori, that pattern priming relies on the posterior cortex that is responsible for relatively early ("presemantic") visual processing. Despite the fact that the pattern priming task that we used in this experiment required fine motor control of the hand, we discounted motor areas as candidate loci for the learning observed on this task because the learning takes place in a single trial and motor learning requires many repetitions of a movement for learning to be expressed (Corkin 1968; Gabrieli et al. 1993). Previous work in our laboratory indicates that AD subjects show normal learning on a test of perceptual identification priming with pseudowords, which are presumed to be novel to the subjects (Keane et al. 1994). Thus, we predicted in the present experiment that we would find intact pattern priming in $\mathrm{AD}$.

\section{Materials and Methods}

\section{SUBJECTS}

The participants in this study were 23 subjects with $\mathrm{AD}$ and 26 normal control subjects (NCSs) (Table 1). The AD subjects, referred from the Memory Disorders Unit at the Massachusetts General Hospital, met established criteria for the clinical diagnosis of probable $\mathrm{AD}$ (McKhann et al. 1984; Khachaturian 1985). All AD subjects re-

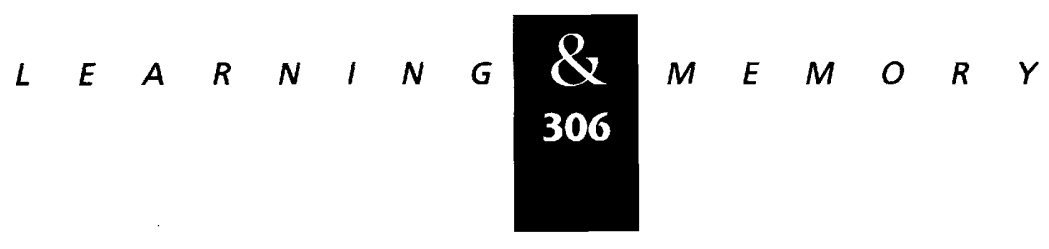


Table 1: Subject characteristics

\begin{tabular}{lllccc}
\hline Group & $\begin{array}{l}\text { Mean age } \\
\text { (S.D.) }\end{array}$ & $\begin{array}{l}\text { Mean education } \\
\text { (S.D.) }\end{array}$ & $\begin{array}{l}\text { Mean BDS: IMC } \\
\text { (S.D.) }\end{array}$ & $\begin{array}{l}\text { Mean duration of disease } \\
\text { (S.D.) }\end{array}$ \\
\hline NCS & 26 & 68.8 & 15.1 & .4 & - \\
& $(13,13)$ & $(8.4)$ & $(2.9)$ & $(.6)$ & 3.5 \\
AD & 23 & 71.7 & 15.2 & 11.6 & $(3.1)$ \\
\hline
\end{tabular}

ablessed Dementia Scale: Information, Memory, and Concentration Section (Blessed et al. 1968).

ceived a neurological examination, either magnetic resonance or computed tomography brain scan, and laboratory tests to rule out other causes of dementia. The severity of dementia in the AD subjects was assessed with the information, memory, and orientation section of the Blessed Dementia Scale [BDS (IMC); Blessed et al. 1968]. AD subjects and NCSs did not differ in terms of mean age or mean years of education. Although abnormalities in visual perception can accompany AD (Katz and Rimmer 1989; Mendez et al. 1990; Kurylo et al. 1994a, 1996; Cronin-Golomb et al. 1995), recent work suggests that AD subjects are not impaired on a task requiring synthesis of a shape from a sparse amount of information (Kurylo et al. 1994b), the principal demand of our task. Many researchers have observed that a subset of AD subjects have visuospatial deficits disproportionately severe in comparison to their cognitive deficits (e.g., Martin et al. 1986; Martin 1990; Mendola et al. 1995). A small number of AD subjects had a visuospatial impairment that was so severe they were unable to execute the simple "copying" procedure required by this experiment. They were, therefore, excluded from the study on the grounds that they were untestable.

\section{STIMULUS MATERIALS}

The stimuli were derived from six dot patterns, each consisting of five dots of the possible nine in a $3 \times 3$ square matrix (Garner and Clement 1963). We created three target stimuli from each dot pattern by connecting the dots with straight lines and selected one stimulus from each dot pattern to create three test forms of six stimuli each. An additional 54 stimuli ( 9 from each dot pattern) served as unstudied foils for the Recognition Test (Fig. 1).

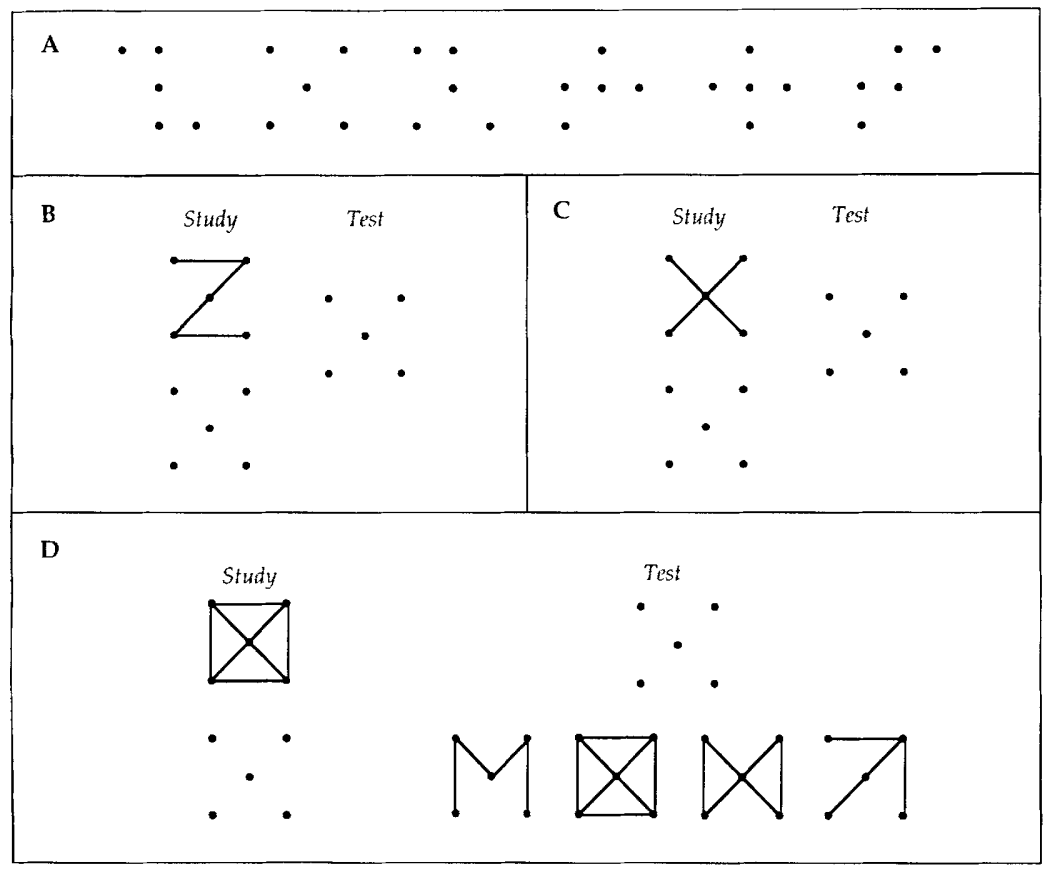

Figure 1: (A) The six dot patterns. (B-D) Examples of the stimuli used on single trials of Priming Test $1(B)$, Priming Test 2 $(C)$, and the Recognition Test (D).

$$
\begin{array}{llllllllllllllll}
\mathcal{Q}_{307} & E & A & R & N & I & N & G & & & & & & & &
\end{array}
$$




\section{PROCEDURE}

The experiment consisted of four sessions: Baseline, Priming Test 1, Priming Test 2, and Recognition Test. The intersession interval was at least $5 \mathrm{hr}$. The two priming tests measured implicit memory; the Recognition Test measured explicit memory. We administered two priming tests in an effort to increase the power of our priming measure because the learning effect seen with pattern priming is small. In the Baseline session subjects viewed each pattern of dots and drew the first figure that came to mind by connecting the dots of each pattern with straight lines (Fig. 1). In Priming Test 1 subjects copied each of the six target figures onto dot patterns, followed by a 3-min distractor task (naming items within the categories of politicians, entertainers, or athletes). Subjects then performed the test phase by drawing the first figure that came to mind onto each of the same six dot patterns (Fig. 1). The percentage of target figures drawn identically to the copied figures yielded a measure of studied completions. If subjects completed a dot pattern to a target figure during the Baseline session, that trial was scored as a baseline completion. The measure of priming was the difference between studied completions and baseline completions. In this way, we ensured that any learning observed during the priming tests was not confounded by a subject's natural predisposition to complete a dot pattern in a particular way. Priming Test 2 followed the same procedure (and used the same dot patterns) as Priming Test 1 but used a different test form and a different fluency category for the distractor test (Fig. 1). The Recognition Test employed the same copy and distractor procedures as the priming tests but with a different test form and a different fluency category. At test, subjects viewed each of the six patterns of dots and indicated by pointing, in a four-alternative forced-choice paradigm, which of four possible completions corresponded to the figure they had copied 3 min earlier (Fig. 1). Test forms were counterbalanced across subjects, so that each of the three forms was used in equal proportions for Priming Test 1, Priming Test 2, and the Recognition Test with each group.

\section{Results}

NCS mean studied completions on Priming Test 1 (21.4\%) differed significantly from mean baseline completions (13.7\%) $(P<0.07)$, and AD mean studied completions (20.4\%) differed significantly from mean baseline completions (11.7\%) $(P=0.01)$, indicating a significant priming effect for each group. Mean studied completions on Priming Test 2 (NCS $=12.9 \% ; \mathrm{AD}=12.3 \%)$, however, did not differ significantly from mean baseline completions. The reduction of studied completions for both groups in Priming Test 2 was attributable to interference from figures studied during Priming Test 1: NCS completed $12.7 \%$ of the dot patterns in Priming Test 2 to figures studied in Priming Test 1 , and AD subjects completed 13.8\% of the dot patterns in Priming Test 2 to figures studied in Priming Test 1. Because of these interference effects, scores from Priming Test 2 were not submitted to further analyses. Further discussion of pattern priming effects will refer to the results from Priming Test 1.

Because non-normal distributions precluded further analysis of the priming results with an ANOVA, we employed nonparametric tests (Wilcoxon Rank-Sum tests) to determine that NCS and AD scores did not differ in mean studied completions $(P>0.8)$ or in mean baseline completions $(P<0.6)$. We tested for an interaction by comparing the mean of the sum of NCS studied completions and $\mathrm{AD}$ baseline completions with the mean of the sum of AD studied completions and NCS baseline completions: A nonsignificant result indicated that the lines linking studied completions and baseline completions in each group were parallel (Fig. 2).

Then, we calculated corrected priming scores by subtracting mean baseline completions from mean studied completions $(\mathrm{NCS}=7.7 \% ; \mathrm{AD}=$ 8.6\%) (Fig. 3). The Spearman correlations between priming score and BDS (IMC) were not significant for either group, nor did a Wilcoxon RankSum test indicate that the two groups differed significantly on the priming measure $(P>0.7)$. Because one cannot prove the null hypothesis, we sought to determine statistically the true difference between NCS and AD priming scores. The difference between the mean scores of the two groups in our study (AD-NCS) was 0.9\% . A 95\% confidence interval indicated that the true difference between the two groups was bounded by a lower confidence limit of $-9.5 \%$ and an upper confidence limit of $11.4 \%$. Thus, with $95 \%$ certainty, we can assert that the true values of the pattern priming scores of the two populations are such that the NCS value does not exceed the AD

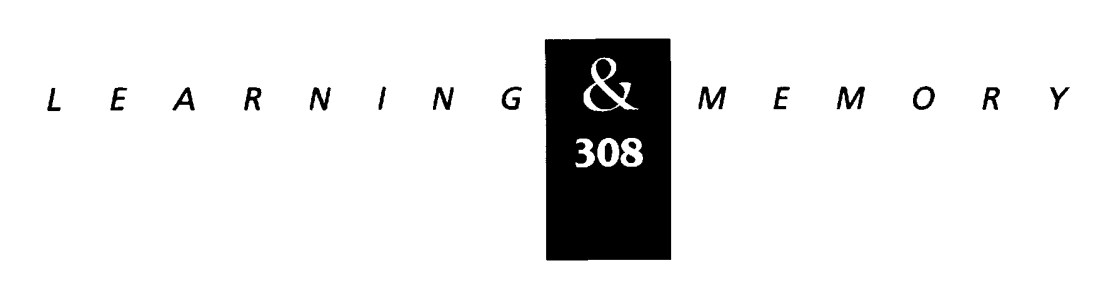




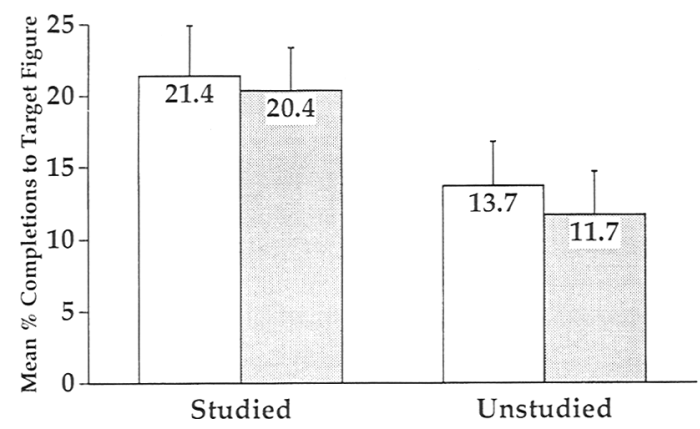

Figure 2: Mean percentage completion patterns to target figures. The priming score for each group is the difference between studied completions and unstudied completions. (Open bars) Control group; (shaded bars) $\mathrm{AD}$.

value by $>9.5 \%$, and the $\mathrm{AD}$ value does not exceed the NCS value by $>11.4 \%$.

The NCSs scored significantly higher on the Recognition Test $($ mean $=55.3 \%$; S.D. $=26 \%)$ than the $\mathrm{AD}$ subjects (mean $=35.7 \%$; s.D. $=25.3 \%$ ), [ $t(47)=-2.6 ; P=0.01]$ (Fig. 3). The correlation between the recognition score and the BDS (IMC) score was not significant for either group.

The correlations between the priming and recognition scores within each group were nonsignificant: NCS, $r=0.2(P>0.2) ; \mathrm{AD}, r=-0.7$ $(P>0.9)$. This result indicates that, for both groups, there was no tendency for subjects who did well on the Recognition Test to do well on the Priming Test 1 nor vice versa.

\section{Discussion}

We investigated pattern priming in $23 \mathrm{AD}$ subjects and 26 NCSs to test the hypothesis that the neural substrate of this nonverbal repetition priming phenomenon is the peristriate cortex. On the measure of implicit memory (Priming Test 1), the $\mathrm{AD}$ and NCS groups achieved comparable performance. On the measure of explicit memory (the Recognition Test), the AD group was significantly impaired relative to the NCS group. This result indicates that pattern priming does not rely on the medial temporal-lobe memory system, which is compromised in $\mathrm{AD}$, and is consistent with results from previous experiments that tested amnesic subjects with etiologies other than AD (Gabrieli et al. 1990; Musen and Squire 1992; Verfaellie et al. 1992; Gooding et al. 1993, 1994). Although demonstrations of stochastic independence are not definitive evidence for the existence of the operation of discrete mnemonic mechanisms (Hintzman 1990), the absence of a significant positive correlation between priming and recognition scores for each group is consistent with the interpretation that subjects relied on different memory processes to perform the two tests in our experiment. A carry-over effect of priming from Priming Test 1 to Priming Test 2-tests that were separated by a minimum of $5 \mathrm{hr}$-indicated that the pattern priming effect was long-lasting, a result that is consistent with previous reports that pattern priming effects can last for 1 week or longer (Musen and Treisman 1990; Gooding et al. 1994). This result suggests that the neural circuits that support this perceptual learning in AD support the same temporal dynamics of learning that are seen in NCSs.

The priming results indicate that implicit memory for novel nonverbal stimuli is preserved in AD subjects: Statistical analyses demonstrated that the priming performance of the two groups was comparable. This finding is consistent with previous studies from our laboratory in which $\mathrm{AD}$ subjects showed intact perceptual identification priming with words and pseudowords (Keane et al. 1991, 1994). In these studies, AD subjects and NCSs studied a list of words or pseudowords and were subsequently able, under tachistoscopic presentation conditions, to identify previously studied stimuli at shorter exposure durations than unstudied stimuli. Testing perceptual identification priming with pseudowords, meaningless combinations of letters that are presumed to be novel to the subjects, employed a similar logic to that employed in the present study. A finding of intact priming with novel stimuli indicates that the learning takes place at a perceptual level of processing, "upstream" (in information processing terms and

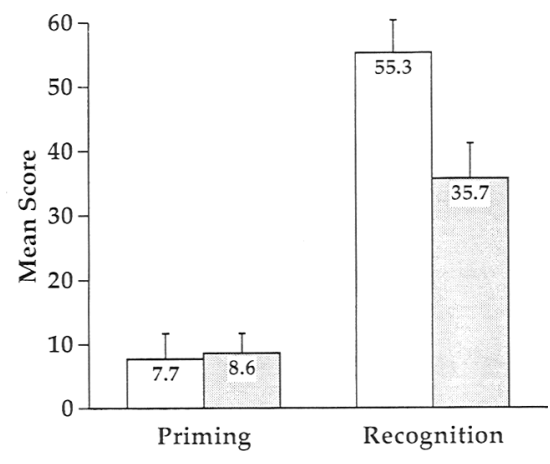

Figure 3: Mean performance by group, on Priming Test 1 and the Recognition Test. (Open bars) Control group; (shaded bars) AD.

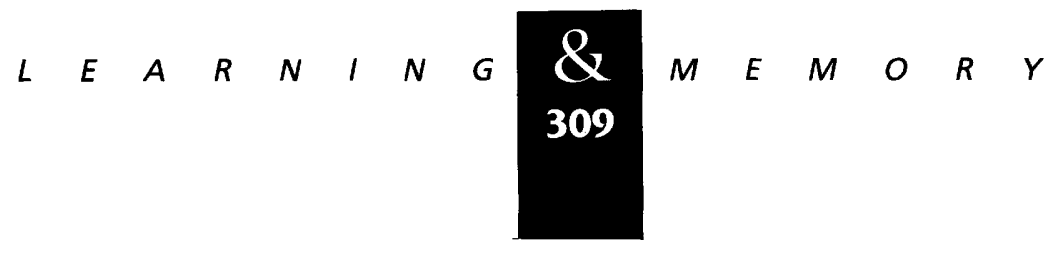


in brain systems terms) from a level where interactions with representations in long-term memory would take place. Taken together, the findings of Keane and colleagues $(1991,1994)$ and those presented in this report indicate that perceptual priming, tested across a broad range of tasks and stimulus types, is preserved in $\mathrm{AD}$ subjects.

The present finding of intact pattern priming in AD subjects suggests that perceptual priming with nonverbal stimuli depends on a brain area that is relatively spared in $\mathrm{AD}$, possibly the peristriate cortex. We have ruled out higher level, heteromodal cortical areas (e.g., inferotemporal and posterior parietal cortex) as candidate substrates for pattern priming because these areas are preferentially vulnerable to AD pathology (Arnold et al. 1991). Consistent with our reasoning are studies of word-stem completion priming that reveal significantly disrupted performance in AD (Keane et al. 1991; Gabrieli et al. 1994). Word-stem completion priming is a type of repetition priming that relies on lexical access (and thus on the integrity of heteromodal temporoparietal cortex ). If pattern priming relied on the same heteromodal temporoparietal areas, we would also expect to see impaired performance in AD on this task. Also consistent with our hypothesis are the results of electrophysiological investigations of nonhuman primates showing plasticity in the response properties of neurons in low-level, unimodal sensory cortex in association with perceptual learning (Recanzone et al. 1992a,b, 1993; G. Bertini, A. Karni, P. De Weerd, R. Desimone, and L.G. Ungerleider, pers. comm.), as well as neuroimaging research in humans that indicates that the neural substrate of structurally mediated verbal priming includes the posterior visual cortex (Squire et al. 1992; Buckner et al. 1995; Schacter et al. 1996).

Although the brain mechanisms that underlie pattern priming in humans cannot be determined using the behavioral methods that we and other researchers have used, physiological research using other experimental paradigms can shape our hypotheses. Positron emission tomography (PET) investigations of word-stem completion priming suggest a mechanism that may also underlie pattern priming. In addition to its lexical access component, word-stem completion priming has a perceptual component (e.g., the effect is reduced by shifts of modality between study and test) (Graf et al. 1985; Bassili et al. 1989; B.R. Postle and S. Corkin, pers. comm.). These PET studies have revealed decreases in blood flow in the peristriate cortex when subjects performed the priming phase of these tests, in comparison with baseline (unprimed) performance (Squire et al. 1992; Buckner et al. 1995; Schacter et al. 1996). These findings have been interpreted as suggesting that the processing of repeated presentations of a stimulus requires less neural activity than was required for the initial processing. Electrophysiological investigations in nonhuman primates have uncovered response properties of single cortical neurons that bear some similarity to these PET findings (Fahy et al. 1993; Li et al. 1993; Miller and Desimone 1994). A recent PET study of nonverbal object priming, however, has found the opposite result. This study revealed blood flow increases in the inferior temporal and fusiform gyri in association with priming on a "possible/impossible" object decision task (Schacter et al. 1995). Thus, although further physiological investigations coupled with careful experimental design need to be carried out, we can postulate that the phenomenon of pattern priming may result from an alteration in the activity of the networks of neurons in posterior regions of the visual system that are recruited to accomplish the perceptual grouping that is necessary to perceive a pattern of scattered dots as a coherent whole.

\section{Acknowledgments}

This research was supported by National Institutes of Health (NIH) grant AG 06605. The MIT Clinical Research Center (CRC) was supported by NIH grant RR00088. Some NCSs were recruited from the Harvard Cooperative Program on Aging (supported by NIH grant AG08812). B.R.P. received support from a National Science Foundation Graduate Research Fellowship. We thank Robert Sugiura and Jeffrey Bucci for assistance in scheduling and testing subjects, Joseph Locascio for consultation on statistical analyses, an anonymous reviewer for helpful comments on an earlier draft of this paper, and the CRC staff for patient care. B.R.P. fondly dedicates this paper to the memory of John Condry, whose advice and encouragement fostered B.R.P.'s entry into science.

The publication costs of this article were defrayed in part by payment of page charges. This article must therefore be hereby marked "advertisement" in accordance with 18 USC section 1734 solely to indicate this fact.

\section{References}

Arnold, S.E., B.T. Hyman, J. Flory, A.R. Damasio, and G.W Van Hoesen. 1991. The topographical and neuroanatomical distribution of neurofibrillary tangles and neuritic plaques in the cerebral cortex of patients with Alzheimer's disease. Cereb. Cortex 1: 103-116.

Bassili, J.N., M.C. Smith, and C.M. MacLeod. 1989.

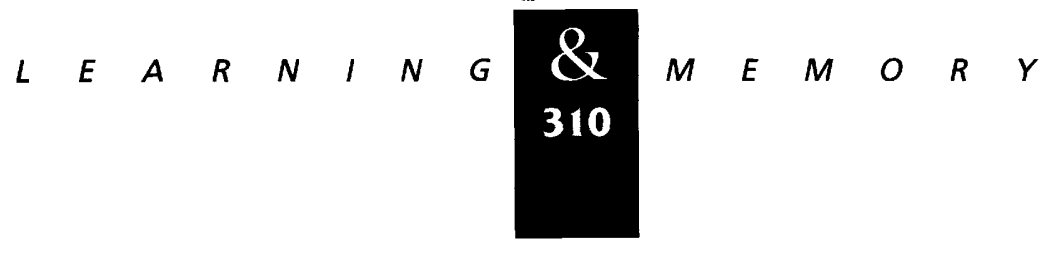


Auditory and visual word-stem completion: Separating data-driven and conceptually driven processes. Quart. J. Exp. Psychol. 41A: 439-453.

Blessed, G., B.E. Tomlinson, and M. Roth. 1968. The association between quantitative measures of dementia and of senile change in the grey matter of elderly subjects. $\mathrm{Br}$. /. Psychiat. 114: 797-811.

Braak, H. 1980. Architectonics of the human telencephalic cortex. Springer-Verlag, New York, NY.

Buckner, R.L., S.E. Petersen, J.G. Ojemann, F.M. Miezen, L.R. Squire, and M.E. Raichle. 1995. Functional anatomical studies of explicit and implicit memory retrieval tasks. J. Neurosci. 15: 12-29.

Corkin, S. 1968. Acquisition of motor skill after bilateral medial temporal-lobe excision. Neuropsychologia 6: $255-265$.

Cronin-Golomb, A., S. Corkin, and J.H. Growdon. 1995. Visual dysfunction predicts cognitive deficits in Alzheimer's disease. Optom. Vis. Sci. 72: 168-176.

Fahy, F.L., I.P. Riches, and M.W. Brown. 1993. Neuronal activity related to visual recognition memory: Long-term memory and the encoding of recency and familiarity information in the primate anterior and medial inferior temporal and rhinal cortex. Exp. Brain Res. 96: 457-472.

Gabrieli, J.D.E., W. Milberg, M.M. Keane, and S. Corkin. 1990. Intact priming of patterns despite impaired memory. Neuropsychologia 5: 417-427.

Gabrieli, J.D.E., S. Corkin, S.F. Mickel, and J.H. Growdon. 1993. Intact acquisition and long-term retention of mirror-tracing skill in Alzheimer's disease and in global amnesia. Behav. Neurosci. 107: 899-910.

Gabrieli, J.D.E., M.M. Keane, B.Z. Stanger, M.M. Kjelgaard, S. Corkin, and J.H. Growdon. 1994. Dissociations among structural-perceptual, lexical-semantic, and event-fact memory systems in Alzheimer, amnesic, and normal subjects. Cortex 30: 75-103.

Gabrieli, J.D.E., D.A. Fleischman, M.M. Keane, S.L. Reminger, and F. Morrell. 1995. Double dissociation between memory systems underlying explicit and implicit memory in the human brain. Psychol. Sci. 6: 76-82.

Garner, W.R. and D.E. Clement. 1963. Goodness of pattern and pattern uncertainty. J. Verbal Learn. Verbal Behav. 2: $446-452$.

Gooding, P.A., R. van Eijk, A.R. Mayes, and P. Meudell. 1993. Preserved pattern completion priming for novel, abstract geometric shapes in amnesics of several aetiologies. Neuropsychologia 31: 789-810.

Gooding, P.A., A.R. Mayes, and P. Meudell. 1994. Long lasting indirect memory performance for abstract shapes in amnesics and matched controls. Neuropsychologia 32: 1135-1143.

Graf, P., A.P. Shimamura, and L.R. Squire. 1985. Priming across modalities and priming across category levels: Extending the domain of preserved function in amnesia. I. Exp. Psychol. Learn. Mem. Cog. 11: 386-396.

Grafton, S.T., E. Hazeltine, and R. Ivry. 1995. Functional mapping of sequence learning in normal humans. J. Cog. Neurosci. 7: 497-510.

Haist, F., G. Musen, and L.R. Squire. 1991. Intact priming of words and nonwords in amnesia. Psychobiology 19: $275-285$.

Hintzman, D.L. 1990. Human learning and memory: Connections and dissociations. Annu. Rev. Psychol. 41: 109-139.

Karni, A., G. Meyer, P. Jezzard, M.M. Adams, R. Turner, and L.G. Ungerleider. 1995. Functional MRI evidence for adult motor cortex plasticity during motor skill learning. Nature 377: 155-158.

Katz, B. and S. Rimmer. 1989. Ophthalmologic manifestations of Alzheimer's disease. Surv. Ophthalmol. 34: $31-43$.

Keane, M.M., J.D.E. Gabrieli, A.C. Fennema, J.H. Growdon, and S. Corkin. 1991. Evidence for a dissociation between perceptual and conceptual priming in Alzheimer's disease. Behav. Neurosci. 105: 326-342.

Keane, M.M., J.D.E. Gabrieli, J.H. Growdon, and S. Corkin. 1994. Priming in perceptual identification of pseudowords is normal in Alzheimer's disease. Neuropsychologia 32: $343-356$.

Keane, M.M., J.D.E. Gabrieli, H. Mapstone, K. Johnson, and S. Corkin. 1995. Double dissociation of memory capacities after bilateral occipital-lobe or medial temporal-lobe lesions. Brain 118: 1129-1148.

Khachaturian, Z.S. 1985. Diagnosis of Alzheimer's disease. Arch. Neurol. 42: 1097-1105.

Kurylo, D.D., S. Corkin, R.P. Dolan, J.F. Rizzo III, S.W. Parker, and J.H. Growdon. 1994a. Broad-band visual capacities are not selectively impaired in Alzheimer's disease. Neurobiol. Aging 15: 305-311.

Kurylo, D.D., S. Corkin, and J.H. Growdon. 1994b. Perceptual organization in Alzheimer's disease. Psychology Aging 9: 562-567.

Kurylo, D.D., S. Corkin, J.F. Rizzo III, and J.H. Growdon. 1996. Greater relative impairment of object recognition than of visuospatial abilities in Alzheimer's disease. Neuropsychology 10: 74-81.

Li, L., E.K. Miller, and R. Desimone. 1993. The 
representation of stimulus familiarity in anterior inferior temporal cortex. J. Neuropsyiol. 69: 1918-1929.

Martin, A. 1990. Neuropsychology of Alzheimer's disease: The case for subgroups. In Modular deficits in Alzheimer-type dementia (ed. M.F. Swartz), pp. 143-175. MIT Press, Cambridge, MA.

Martin, A., P. Brouwers, F. Lalonde, C. Cox, Pl. eleska, P. Fedio, N.L. Foster, and T.N. Chase. 1986. Toward a behavioral typology of Alzheimer's patients. I. Clin. Exp. Neuropsychol. 8: 594-610.

McKhann, G., D. Drachman, M. Folstein, R. Katzman, D. Price, and E.M. Stadlan. 1984. Clinical diagnosis of Alzheimer's disease: Report of the NINCDS-ADRDA work group under the auspices of the Department of Health and Human Services task force on Alzheimer's disease. Neurology 34: 939--944.

Mendez, M.F., R.L. Tomsak, and B. Remler. 1990. Disorders of the visual system in Alzheimer's disease. 1. Clin. Neurolog. Ophthalmol. 10: 62-69.

Mendola, J.D., A. Cronin-Golomb, S. Corkin, and J.H. Growdon. 1995. Prevalence of visual deficits in Alzheimer's disease. Optom. Vis. Sci. 72: 155-167.

Mesulam, M.-M. 1985. Patterns in behavioral neuroanatomy: Association areas, the limbic system, and hemispheric specialization. In Principles of behavioral neurology (ed. M.M. Mesulam), pp. 1-71. F.A. Davis, Philadelphia, PA.

Miller, E.K. and R. Desimone. 1994. Parallel neuronal mechanisms for short-term memory. Science 263: 520-522.

Milner, B., S. Corkin, and H.-L. Teuber. 1968. Further analysis of the hippocampal amnesic syndrome: 14-year follow-up study of H.M. Neuropsychologia 6: 215-234.

Musen, G. and A. Treisman. 1990. Implicit and explicit memory for visual patterns. J. Exp. Psychol. Learn. Mem. Cognit. 16: 127-137.

Musen, G. and L.R. Squire. 1992. Nonverbal priming in amnesia. Mem. Cognit. 20: 441-448.

Recanzone, G.H., W.M. Jenkins, G.H. Hradek, and M.M. Merzenich. 1992a. Progressive improvement in discriminative abilities in adult owl monkeys performing a tactile frequency discrimination task. I. Neuropsychol. 67: 1015-1030.

Recanzone, G.H., M.M. Merzenich, and C.E. Schreiner. 1992b. Changes in the distributed temporal response properties of SI cortical neurons reflect improvements in performance on a temporally based tactile discrimination task. J. Neuropsychol. 67: 1071-1091.

Recanzone, G.H., C.E. Schreiner, and M.M. Merzenich. 1993. Plasticity in the frequency representation of primary auditory cortex following discrimination training in adult owl monkeys. J. Neurosci. 13: 87-103.
Schacter, D.L. 1992. Priming and multiple memory systems: Perceptual mechanisms of implicit memory. J. Cog. Neurosci. 4: $244-256$.

Schacter, D.L., E. Reiman, A. Uecker, M.R. Polster, L.S. Yun, and L.A. Cooper. 1995. Brain regions associated with retrieval of structurally coherent visual information. Nature 376: $587-590$.

Schacter, D.L., N.M. Alpert, C.R. Savage, S.L. Rauch, and M.S. Albert. 1996. Conscious recollection and the human hippocampal formation: Evidence from positron emission tomography. Proc. Natl. Acad. Sci. 93: 321-325.

Squire, L.R. 1992. Memory and the hippocampus: A synthesis from findings with rats, monkeys, and humans. Psychol. Rev. 99: 195-231.

Squire, L.R., J.G. Ojemann, F.M. Miezin, S.E. Petersen, T.O. Videen, and M.E. Raichle. 1992. Activation of the hippocampus in normal humans: A functional anatomical study of memory. Proc. Natl. Acad. Sci. 89: 1837-1841.

Ungerleider, L. 1995. Functional brain imaging studies of cortical mechanisms for memory. Science 270: 769-775.

Verfaellie, M., W.P. Milberg, L.S. Cermak, and L.L. Letourneau. 1992. Priming of spatial configurations in alcoholic Korsakoff's amnesia. Brain Cog. 18: 34-45.

Warrington, E.K. and L. Weiskrantz. 1970. Amnesic syndrome: Consolidation or retrieval? Nature 228: 628-630.

Received April 12, 1996; accepted in revised form August 23, 1996.

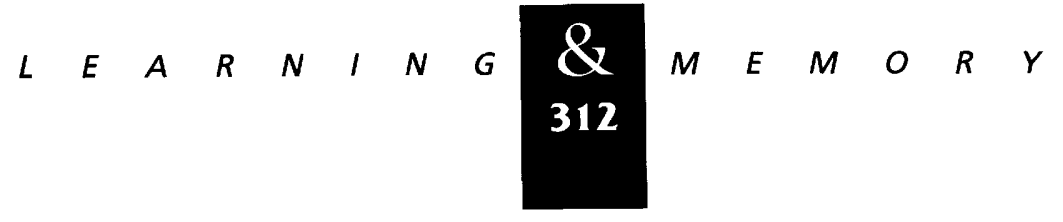




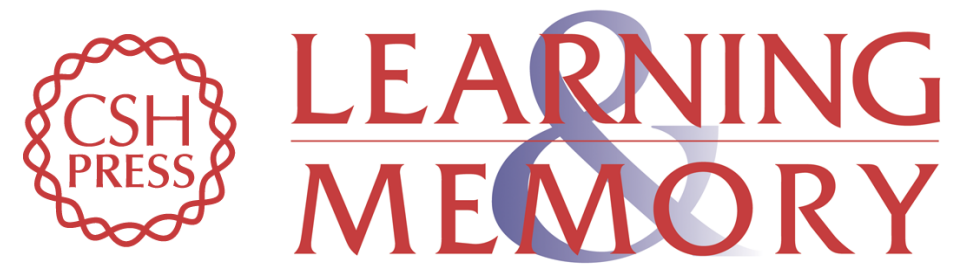

\section{Intact implicit memory for novel patterns in Alzheimer's disease.}

B R Postle, S Corkin and J H Growdon

Learn. Mem. 1996, 3:

Access the most recent version at doi:10.1101//m.3.4.305

References This article cites 47 articles, 8 of which can be accessed free at: http://learnmem.cshlp.org/content/3/4/305.full.html\#ref-list-1

License

Email Alerting Receive free email alerts when new articles cite this article - sign up in the box at the Service top right corner of the article or click here. 